$$
\begin{aligned}
& 50 \\
& 433 \\
& .45 \\
& 1022
\end{aligned}
$$

Forect jeroducls Laboratory 


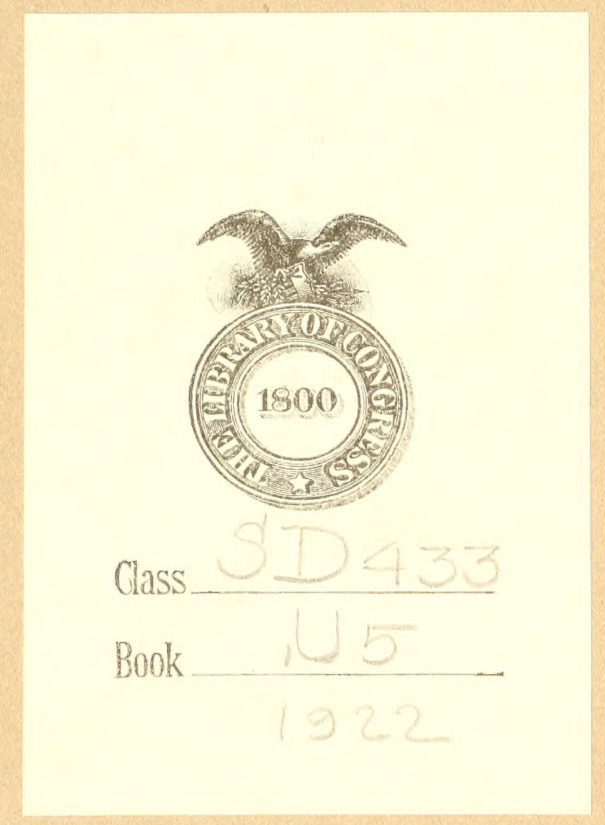




\begin{tabular}{|c|} 
LIERARY OF CONGRESS \\
PECSIVED \\
APR 291922 \\
DOOUMENT'S L.V.SION
\end{tabular}

(O) 


\section{FOREST PRODUCTS LABORATORY}

A BRIEF ACCOUNT OF ITS WORK AND AIMS

THE FOREST PRODUCTS LABORATORY is a unit in the Branch of Research of the Forest Service, United States Department of Agriculture. It is located at Madison, Wis., and is conducted in cooperation with the University of Wisconsin.

\section{Public Service.}

THE purpose of the Forest Service in the administration of the Forest Products Laboratory is to conserve American forests by developing the most Scope of economical methods of converting standing trees into finished products. The purpose is also to make the growing of timber more profitable by increasing the possibilities in the utilization of both used and unused species. The Laboratory seeks to develop not only new and more efficient processes, but to find ways of utilizing material which would otherwise be wasted, to find new uses for old materials and new materials for old uses. In a word, the aim is to render practical assistance to the manufacturers and users of wood and wood products and at the same time to promote forest conservation and the practice of forestry.

Every American industry and class of consumers which uses or grows wood or any other product of the forest may thus be a beneficiary of the work done at the Laboratory. Every such industry, class of consumers, and timber producers is a potential cooperator in the Laboratory's work. Its objects are sought not only through experiments conducted at the Laboratory but also through the detail of its men to work on 
Value of Work.

Results Available to Public.

Place in Forest Conservation. important problems in the mills and factories and the receiving of representatives of the industries at the Laboratory to work beside its scientific men.

The value of this work has already made itself apparent. The reduction of waste, the better utilization of the products of the tree, the utilization of species hitherto wasted, the added life given to many kinds of wood products by more efficient preservative methods, the reduction of the degrade in lumber by efficient dry-kiln methods, and many other savings are an enormous help in conserving our timber supply. The financial advantage to industries and consumers may be indicated by an example. If the methods of nailing boxes recommended by the Forest Products Laboratory and adopted by the National Association of Box Manufacturers saves but 1 per cent of the annual loss for claims and damages in shipments actually paid by the railroads, the saving will be $\$ 1,000,000$ a year. It has been estimated that the total annual saving as a result of the work of the Laboratory has already reached not less than $\$ 30$,000,000 .

The value of the Forest Products Laboratory to any particular wood-using industry or class of consumers depends to a very large extent upon the use which that industry makes of it. It is a Government institution supported mainly by Government appropriations, and its advice and suggestions are to be had for the asking. It presents an opportunity for every manufacturer, user, and timber grower to supplement the information obtained by experience and hard knocks, with technical data obtained through scientific research.

The work of the Laboratory is of direct value to those engaged in timber production. To a very large extent the kinds and sizes of forest trees which should be grown and the purposes for which they should be produced are dependent on the mechanical, physical, and chemical properties of their woods and the uses to 


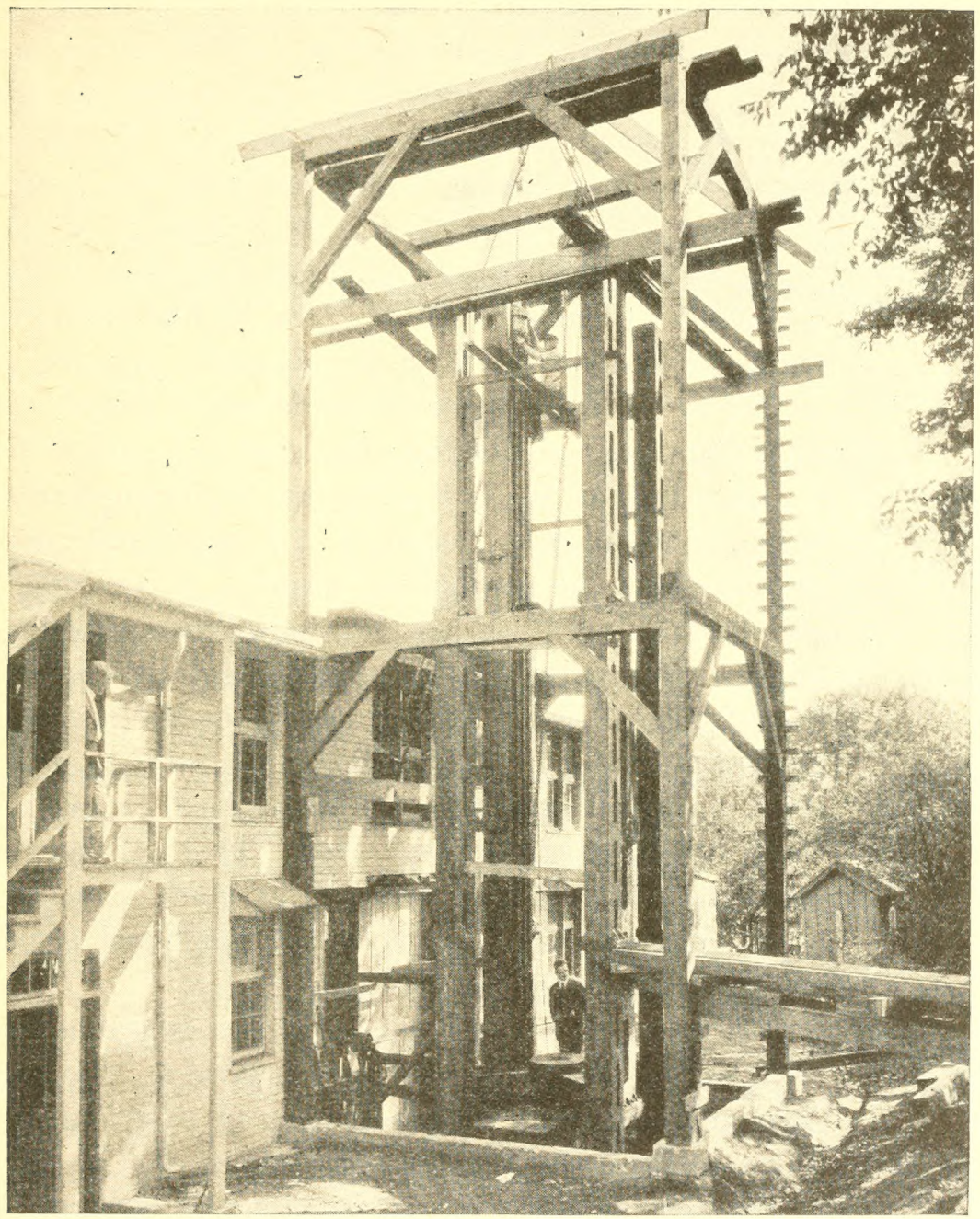

The largest of the testing machines, shown here in the process of erection, is capable of exerting a force of a million pounds and can test to destruction wooden columns 30 feet long and a foot square. 
which they can most profitably be put. In the administration of the National Forests and of privately owned timberlands, in the activities of the State Forestry departments, and in the instruction given by the forest schools, the results secured by the Laboratory play an important part. By reducing the present waste of three-fourths of every tree cut and making possible the most efficient utilization of the one-fourth used they are contributing in a very essential way to forest conservation and to profitable timber production. Through its forest products research the Forest Service supplements its efforts to bring about the growing of timber by information which should make possible the most complete and effective utilization.

Allied Problems.

In the 11 years the Laboratory has been in operation it has accumulated a vast store of fundamental information about the mechanical, physical, and chemical properties of wood. It has also studied the application of this information to the problems involved in the manufacture of wood products and chemical products derived from wood. In studying manufacturing problems, materials used with the wood often require as much attention as the wood itself. This has necessitated the study of such subjects as glues, moistureproof coatings, wood preservatives, laminated wood, and fire-retarding materials.

Laboratory Established in 1910.

The Forest Products Laboratory was established in 1910 by the United States Forest Service at Madison, Wis., in cooperation with the University of Wisconsin. For several years it was the only institution of its kind in the world conducted with the object of turning the searchlight of research upon wood and its uses and making the information thus obtained available to the public.

In this publication is presented a general outline of the aims and scope of work of the organization. 


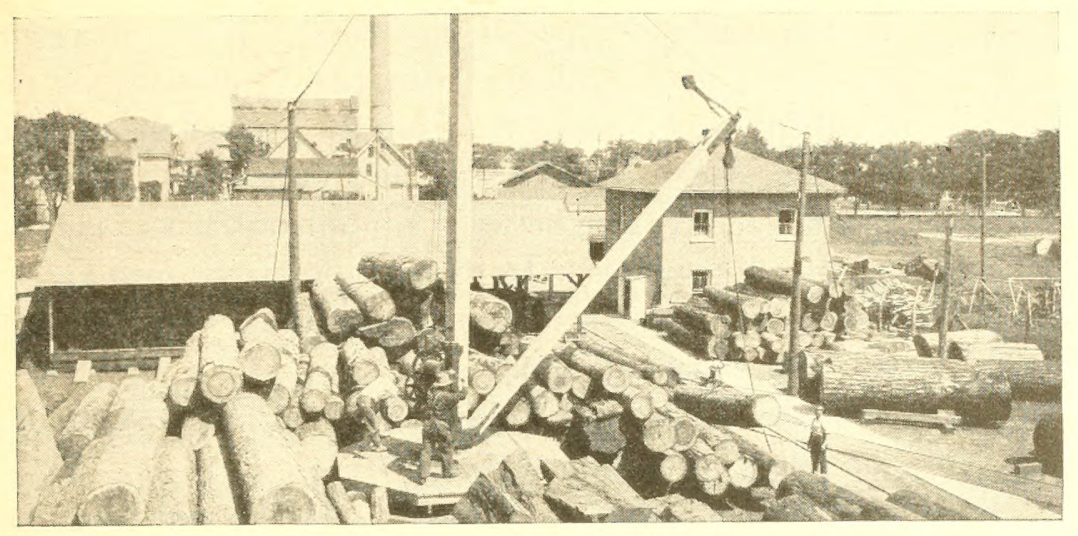

\section{Organization for Research.}

$\mathbf{R}$ ESEARCH is increasingly effective in proportion as it is carefully planned and executed. At the Coordinated $\mathrm{Re}$ search.

beginning of each year a program covering as nearly as practicable the work of the Laboratory for the ensuing year is considered and approved. Individual initiative and responsibility are given the widest possible opportunity, but at the same time the work of different men is so coordinated by an interchange of ideas among the different sections, and other means, that duplication is avoided and cumulative results are obtained.

A carefully worked out system for keeping a check on the status, progress, and correlation of investigative activities and for guiding interrelated projects through the Laboratory has been adopted. Systematically planned programs and carefully coordinated type of organization is in a large measure responsible for the practical value of the work already accomplished.

The Laboratory is in charge of a director, an assistant director, and a staff comprised of the heads of the different research and administrative sections. In each section are men of broad general experience with wood and knowledge of its characteristics, and other specialists in various wood uses, who devote their whole time

Organization of the Laboratory. 
to the study of special problems. These men are recruited, in accordance with the regulations of the Civil Service Commission, from the professions of engineering, chemistry, forestry, and pathology. A sharp distinction is drawn between administrative and investigative assignments. In this way, research men are relieved of other cares and can give their whole thought to the problems in hand.

The work of the Laboratory is distributed among the following technical sections:

Timber mechanics. - Strength of wood and manufactured articles.

Timber physics.--Experimental and applied kilndrying, physical properties, identification, and structure of wood.

Wood preservation.-Wood treatments, glues, and laminated construction.

Pulp and paper.-Manufacturing methods and suitability of various woods for pulp, paper, and special products.

Derived products.-Chemical properties and uses of wood and chemical wood products, such as turpentine, alcohol, acetic acid, etc.

Industrial investigations.-Methods and practices in the lumber and other wood-using industries, grades, specifications, and mill scale studies.

Pathology (in cooperation with the Bureau of Plant Industry).-Decay of timber, molds, stains in manufactured wood products, and antiseptic properties of wood preservatives.

In addition, there is a section of Laboratory operations which handles the administrative work involved in accounting, engineering, photography, computing, records, supplies, and the maintenance of the Laboratory generally. A division in the director's office reviews and coordinates the results secured, prepares material for publication, and in other ways arranges for its most effective dissemination and utilization. 
The work of each technical section is divided into Projects. "projects," each of which is assigned to one or more of the staff. Before one of these projects is undertaken a preliminary investigation is made and a report prepared indicating the nature of the problem, the work done, and results already secured in the same field, and the recommended method of attack.

A part of the effort of each section is devoted to the Commercial development and maintenance of contact with the Demonstralumber-manufacturing and wood-using industries and wood consumers and producers. The resources of the Laboratory are made available to the public through personal contact with the field representatives assigned to study technical problems. Familiarity with the needs of timber growers, wood consumers, and the wood-using industries serves as a guide to direct the investigations made at the Laboratory. 


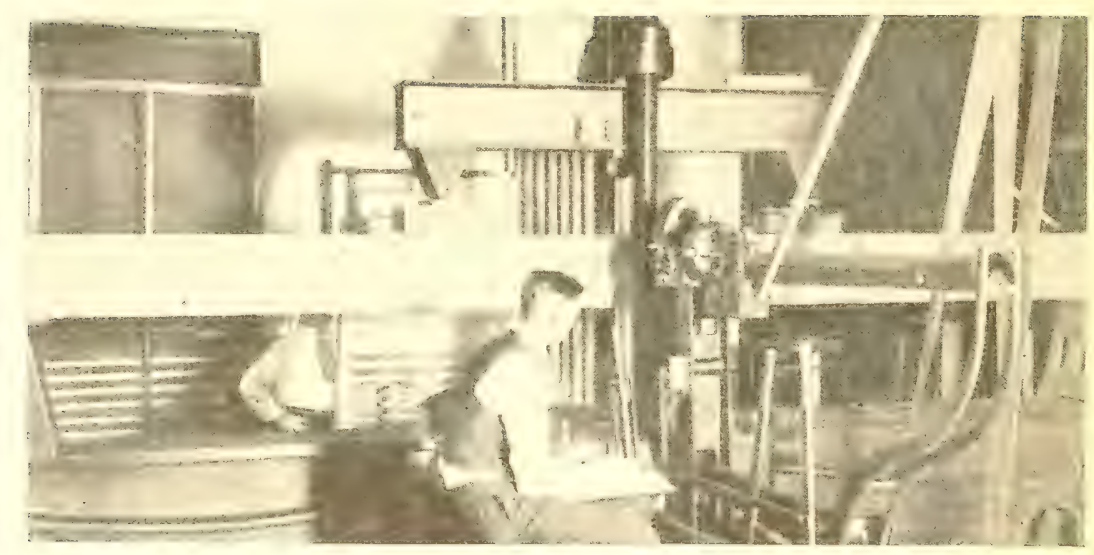

\section{Timber Mechanics.}

Strength of

Various

Species.
KNOWLEDGE of the mechanical properties of woods and wood products is essential for their intelligent and economic use, whether in the factory, on the farm, in the home, on the railroad, in the mine, or in the air. Thus development of the airplane and progress in many other lines depend in a large measure on accurate information as to the strength, toughness, elasticity, and other mechanical properties which determine the suitability of different woods for various purposes. To supply this information, over 500,000 mechanical tests have been made, as nearly as possible under standardized conditions, so that the tests made for a single purpose will have the broadest application and will serve for many uses.

Data from tests of small clear specimens are now available in published form on 126 species of woods grown in the United States and in unpublished form on 23 native species, as well as data, in some cases meager, in some cases fairly complete, on about 60 species, principally from South America and the Philippines. These data are of particular value in comparing the properties of the different species, in finding substitutes for the scarcer and higher-priced woods, in selecting species for particular uses, and in estab- 
lishing correct working stresses. The results of these tests on small, clear specimens also furnish definite information on the variability of wood and show the necessity of grading timber for all uses where strength is of prime importance.

A large number of tests have also been made on full-sized timbers, such as bridge stringers, factorybuilding timbers, and car sills. These tests have demonstrated the influence of defects, such as knots, shakes, and checks on strength; and, altogether with the results of tests on small clear specimens, furnish the basis for the establishment of grading rules and correct working stresses for structural timbers.

Wood is subjected to a great variety of preservative Effect of treatments, to many different drying or seasoning processes, to conditioning treatments in preparation for Treatments on Strength. bending, and to many other processes with particular objects in view. Some of these treatments, particularly those which use high temperatures or high pressures, or both, appreciably lessen the strength of wood and are responsible for large losses. The Laboratory has therefore been studying the effect of such treatments on strength, with special reference to kilndrying and preservative treatments, and, to a smaller extent, methods of conditioning wood for bending. Both commercial sizes and small pieces free from defects are used in these studies. The form and character of the test specimens in each case are as nearly standard as possible, usually varying only in details necessary to make the tests directly applicable to the problem in hand.

Tests have been made on plywood to determine the strength of different combinations of species, the effect of increasing the number of plies, and the effect of varying the ratio of core thickness to total panel thickness. Some data are also available on factors affecting warping, on strength of fastenings for plywood, on the efficiency of joints in plywood, and on 


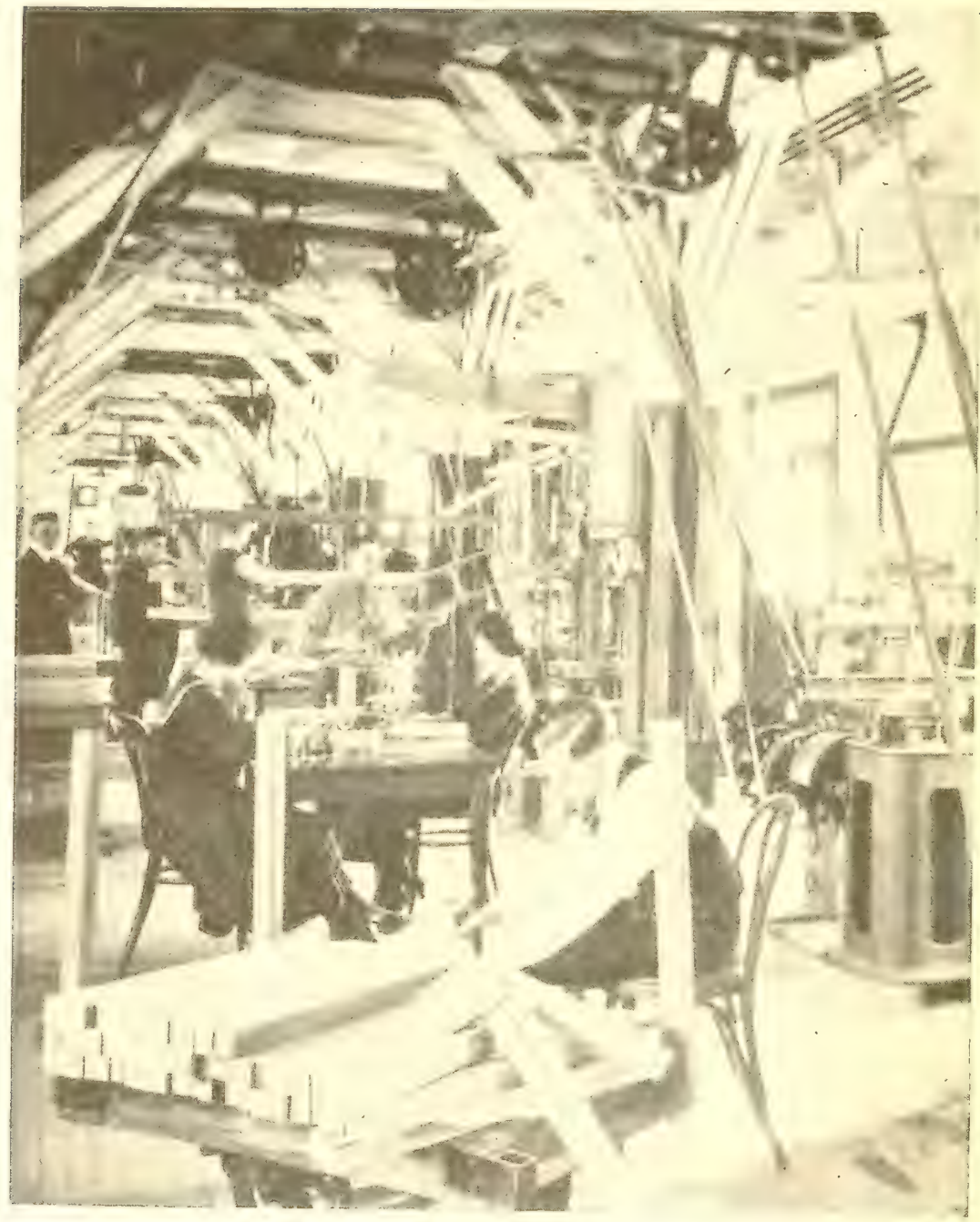

Some of the strength-testing machines, such as the one at the right, are employed chiefly in determining the strength properties of native woods, using small, clear specimens like those on the truck. (Other machines are rigged up to test wooden parts. A newly designed airplane wing rib is just being placed in the machine second in line. 
the strength in tension. Information on such points as these places the Laboratory in a position to assist users and manufacturers of plywood and veneer products in solving problems encountered in developing new uses for these products in the various industries.

The results of tests on containers are of particular interest to all shippers, box manufacturers, and transportation companies and are also of great importance to the public in general. The damage due to the failure of containers in transportation amounts annually to many million of dollars. There are, in addition, large losses due to improper packing. All of the work done at the Laboratory in this field tends directly to reduce these enormous losses, which are ultimately paid by the consumer. A considerable amount of fundamental data relating to the construction of boxes and crates has been obtained, which finds direct application in the redesign of faulty containers and in the development of new containers. It is frequently possible to redesign a container so as to reduce the amount of material required, to save shipping and warehouse space, and at the same time to obtain greater serviceability. The investigations apply to all types of both wooden and fiber boxes and to barrels and crates. One of the interesting facts established by the studies is that a chief source of weakness in wooden containers is inadequate nailing, and that the use of thicker material will not remedy this defect.

Tests on various species have furnished information on their strength, their resistance to splitting, and their ability to hold nails, which has made it possible to classify the woods in groups for box and crate construction.

Revolving-drum tests, together with drop and com- Drum Tests. pression tests of boxes loaded with either actual or dummy contents, have been used in determining the characteristic weakness of the various types of containers. The Forests Products Laboratory standard 


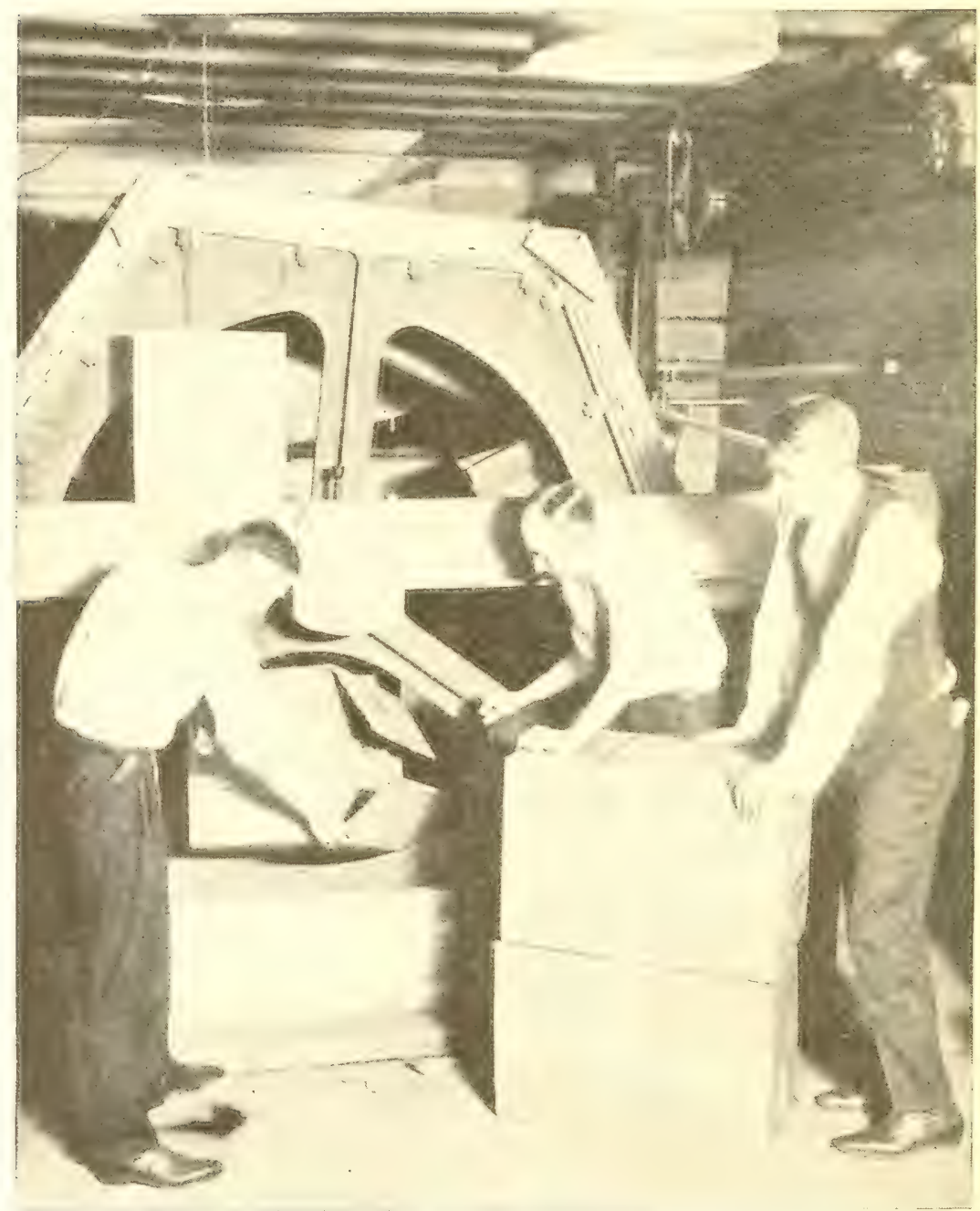

The drum-testing machine, developed by the Laboratory to stimulate the hazards of transportation, has become standard for shippers, packers, and manufacturers. The boxes shown are packed with electric-light bulbs. Four thousand dollars' worth of bulbs were furnished by the electric companies concerned for this series of tests to develop a better container. 


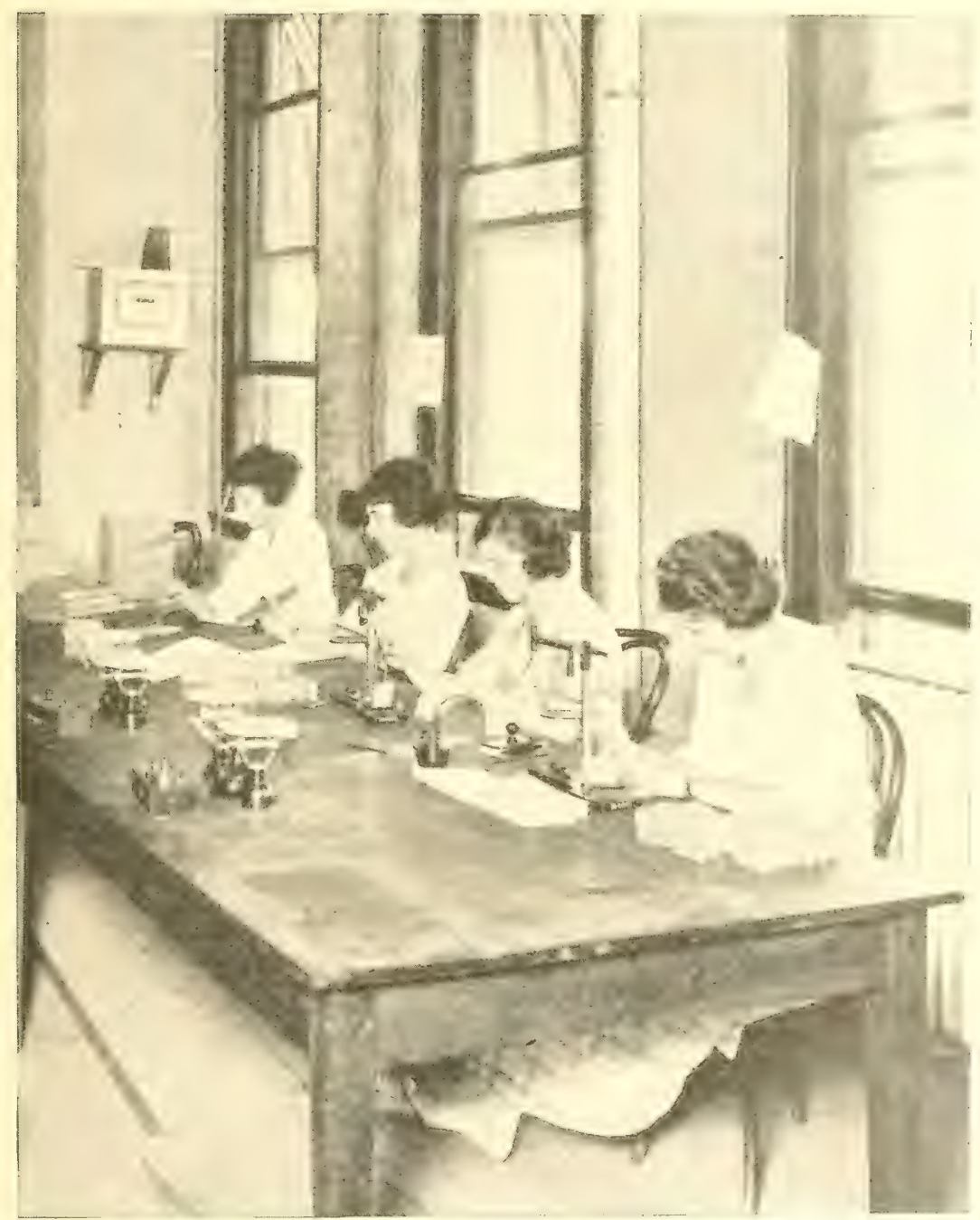

Aside from its value in laboratory tests, the determination of the moisture content of wood is so important in connection with the various uses of wood that every woodworking factory should become familiar with the simple process. A knowledge of the moisture content of the stock often makes it possible to avoid costly manufacturing difficulties. 
drum is 14 feet in diameter and can accommodate packages up to 1,000 pounds in weight. It is fitted with hazards so arranged that the container under test follows a regular cycle of drops which simulate those received in actual transportation. The field for this work is very large, and much remains to be done in order to develop fundamental relations between the weight and the nature of the commodity, the type of box to be used, and the thickness of the bottom, side, and end boards.

Tests of Tests on vehicle and implement parts, airplane parts, Manufac- doors, and other articles manufactured of wood are turedArticles. made primarily to demonstrate the fitness of substitute species, to develop or improve designs, and to obtain more economical and efficient use of wood. Considerable data in published and unpublished form are now available on this subject. The limitations and possibilities of splices and laminated construction are being studied with a view to conserving lumber through the increased use of small pieces and low grades. This should make possible the use of smaller trees, which can be grown in comparatively short periods; in short, the character of material on which the country will have to depend very largely in the future and which can be grown most profitably. 


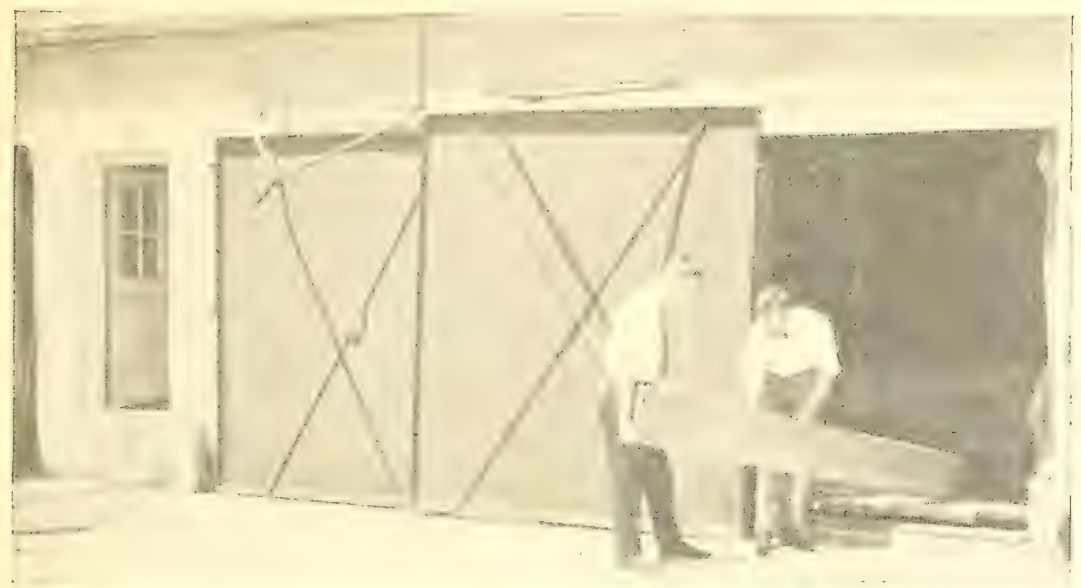

Timber Physics.

A KNOWLEDGE of the physical properties of wood 1 is of importance to almost every industry using wood and is essential in kiln drying, impregnation with preservatives, distillation, and other treatments. Omitting the properties already referred to as mechanical-some of which might equally well be classed as physical-the more distinctly physical properties studied are density, shrinkage, transfusion of moisture, hygroscopicity, specific heat, heat conductivity, heat of absorption of water in wood, and permeability of wood by liquids and gases.

It is often necessary for financial reasons to reduce Kiln Drythe time required properly to season wood by open-air ing.

drying. Moreover, for many purposes it is desirable to dry the wood more thoroughly than is possible in the open air and to employ conditions which will reduce its hygroscopicity, or tendency to shrink and swell. For these reasons dry kilns are almost universally employed for high-grade lumber, and frequently even for the poorer grades. In the drying of hardwoods it is estimated that about 10 per cent of the material dried is either ruined or lowered in grade. Much of this loss could be avoided by proper methods and kilns, 
and the present results might be greatly inproved in other respects.

Establishing The Forest Products Laboratory bases all its kilnScientific Principles. drying practice on fundamental studies to determine the principles underlying the transfusion of moisture through wood, the effect of changes in atmospheric conditions upon the rate of transfusion, the effect of various methods of drying and of various drying treatments upon the properties of the wood being dried, and similar studies. In connection with this work a special type of kiln, known as the water-spray kiln and developed at the Laboratory, has found successful application in many commercial plants where drying requirements are very exacting.

Commercial Studies of commercial types of dry kilns are well Kilns.

under way. These studies are being made to determine the range of usefulness of the various types and to develop improvements wherever possible. General data on the cost of dry-kiln operation are also being obtained in so far as possible.

Drying

Schedules.

A comprehensive series of experiments is being conducted to determine the proper "drying schedules" for all important commercial woods. These drying schedules will show the proper conditions of temperature and humidity to obtain best results in drying, and they will cover the entire range from an absolutely green condition to absolute dryness. A number of drying schedules have already been published. This class of work has direct application throughout the wood-using industries.

In addition to schedules for lumber of various thicknesses, drying schedules are worked out for special purposes, such as the drying of gunstock blanks, wagon-wheel spokes, and felloes. Special schedules are also developed for very high-grade work, like the drying of aircraft stock and parts, where the utmost strength is essential. Experiments have also been made to determine the best commercial 


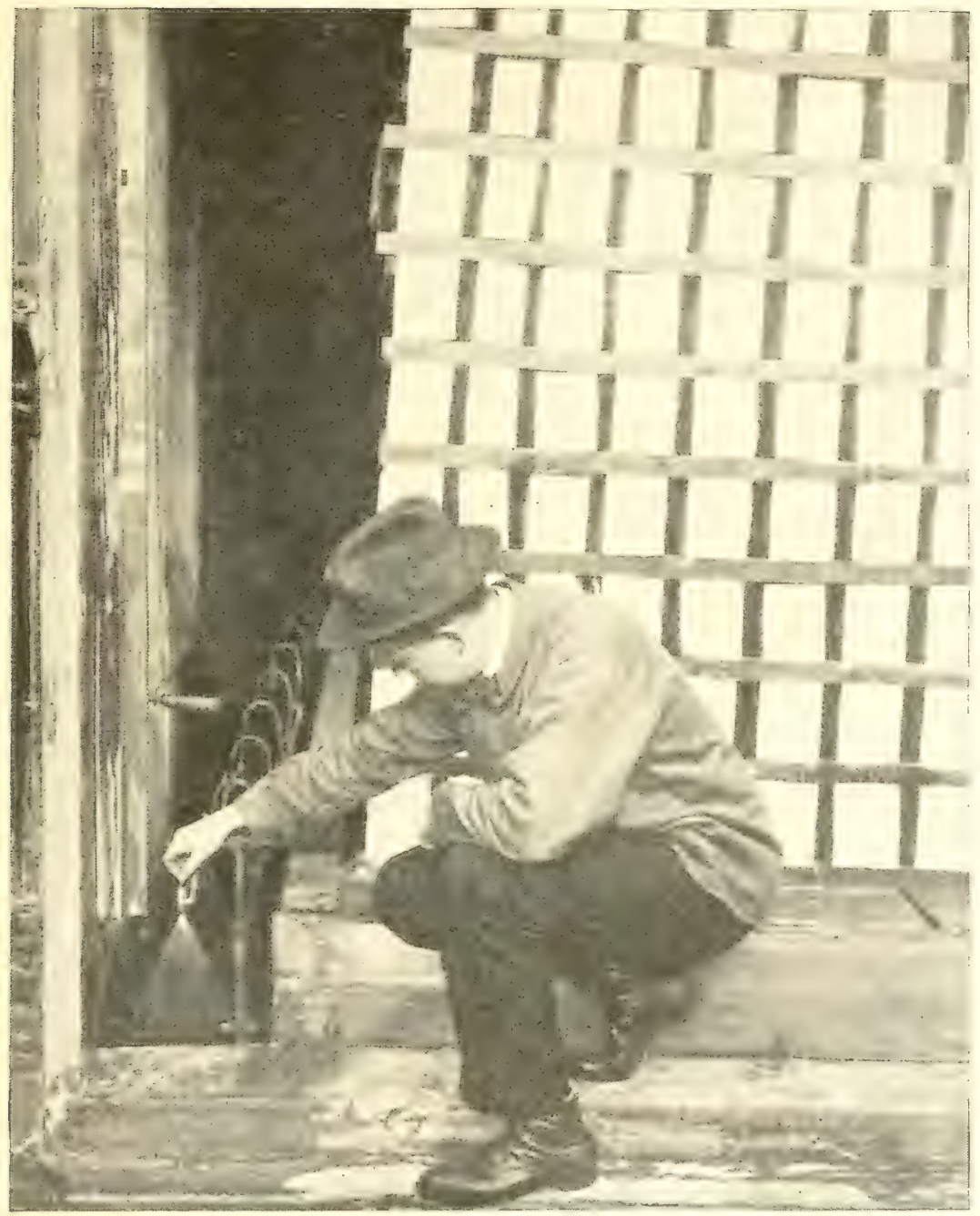

The distinctive feature of the Forest Service water-spray kiln is the control of the humidity in the kiln and, consequently, the drying rate of the lumber, by conditioning the air with sprays of water whose temperature is carefully regulated. The experimental kiln shown is drying oak bolster stock, which appears white because of the end dip used to reduce checking. 
Steam Bending.

Identification.

Relation of Structure to Properties. methods of drying plywood, much of the trouble in the manufacture of which may be traced to faulty or careless drying.

The proper steam bending of heavy wooden parts, such as artillery wheel rims, presents a number of problems on which the Laboratory has done a limited amount of work and on which it plans to do much more in the near future. The proper moisture condirion of the stock, the length and temperature of steaming or other preliminary treatment, and the mechanical details of the actual bending must all be worked out before present high losses in this process can be overcome.

The accurate identification of woods is important not only in the investigative work of the Laboratory, where it is essential that the kind of wood under test be definitely known, but to wood users generally. There is a steadily increasing demand in the various industries for service of this character, and several thousand specimens of wood are annually identified for outside concerns. Microscopic slides and photomicrographs made from the slides have been prepared for practically all American woods of importance and are available for study. Authentic specimens of most species are also available.

Fundamental studies under the microscope to determine the relation of structure to shrinkage have been under way for some time and are nearing successful completion. Similar studies to determine the relation of structure to mechanical and physical properties are under way, and it is hoped that structure and properties may be definitely correlated. 


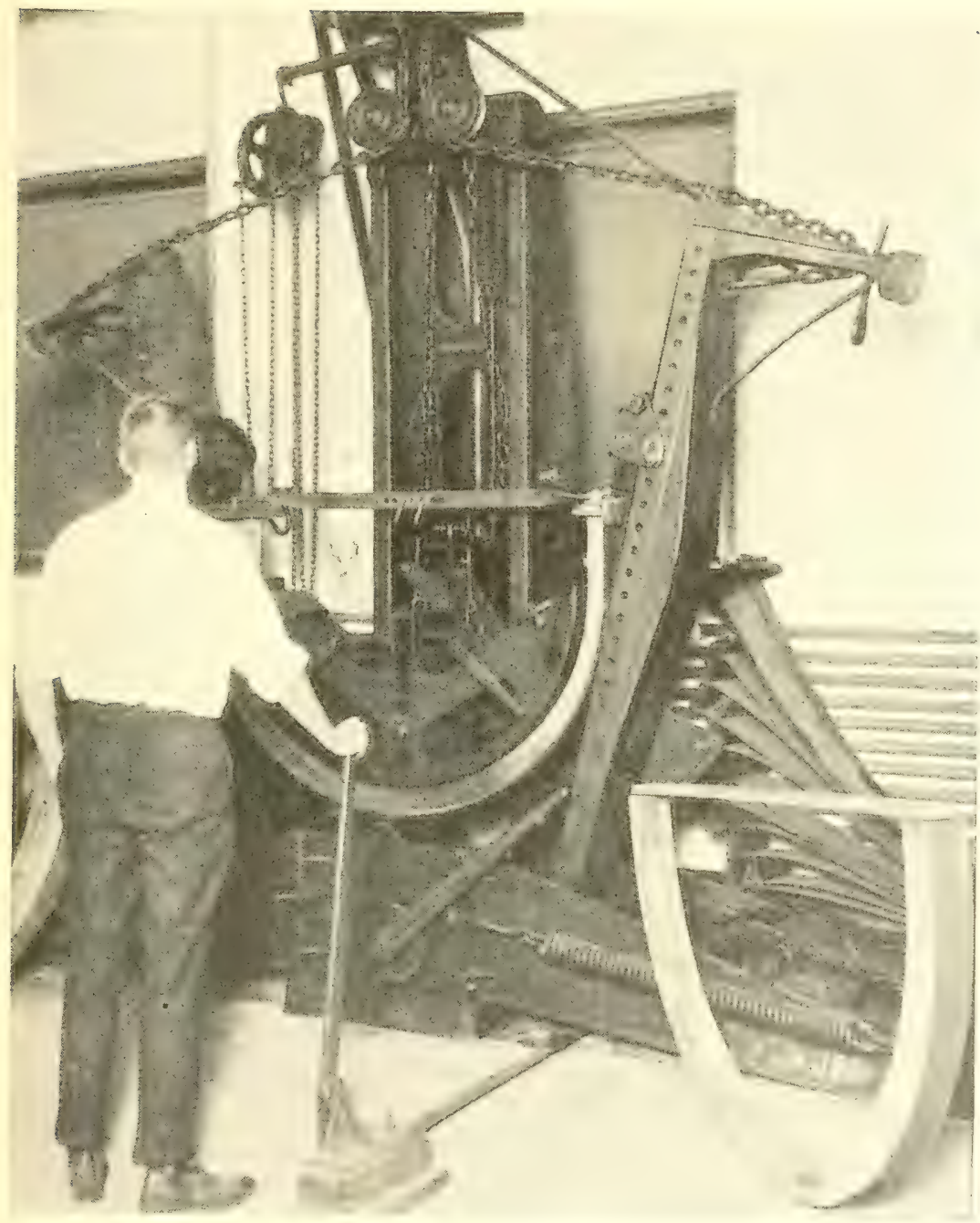

Furniture and vehicle factories are concerned in the research of the Laboratory to reduce losses in the steam bending of stock. To bend a heavy wheel rim, such as is shown, without fracture, requires a careful preliminary conditioning treatment. 


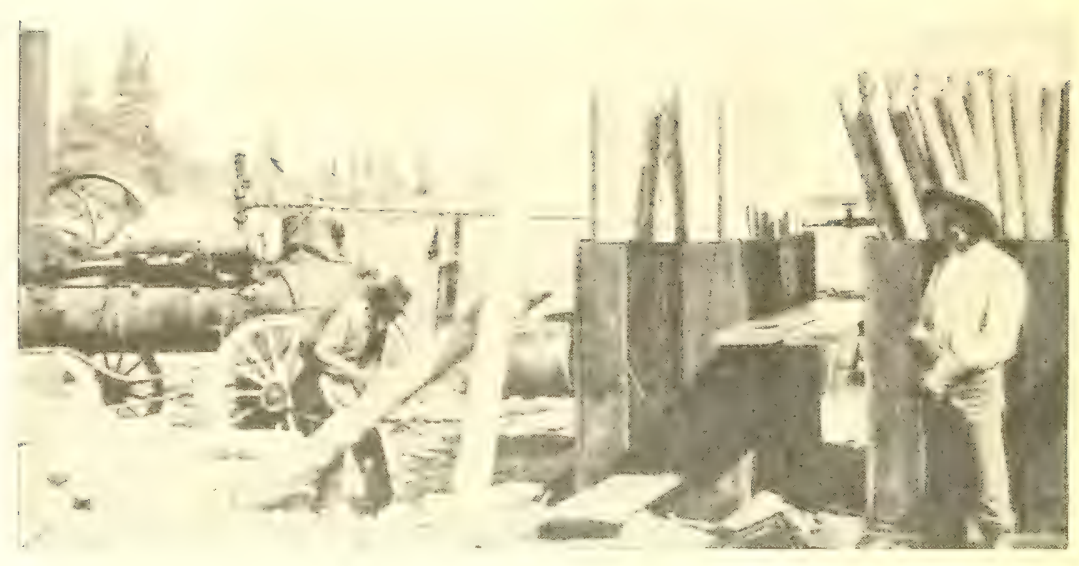

\section{Wood Preservation.}

Preservatives. THE amount of wood in the form of railroad ties, mine timbers, posts, poles, and other products which is destroyed each year by decay is approximately equal to the loss from forest fires. It is therefore important to devise methods of treating wood with preservatives that will reduce this waste to a minimum. An annual saving of $1 / 2$ billion of board feet is estimated to be possible in the case of railroad ties alone, could preservative treatment be extended to the 85 million ties at present untreated.

In treating operations, the cost of the preservative, such as creosote, zinc chloride, or sodium fluoride, amounts to a high percentage of the total cost. Furthermore, the ultimate success of any treatment is largely dependent upon the preservative used. Much information has already been obtained concerning the preservatives now in common use, but there is need for a great deal of further study with the object of developing new preservatives which will either be cheaper or more effective than present preservatives, or will have properties fitting them for wider use or for special purposes. The value of a preservative is not considered established until it has had a thorough trial under actual service conditions. 


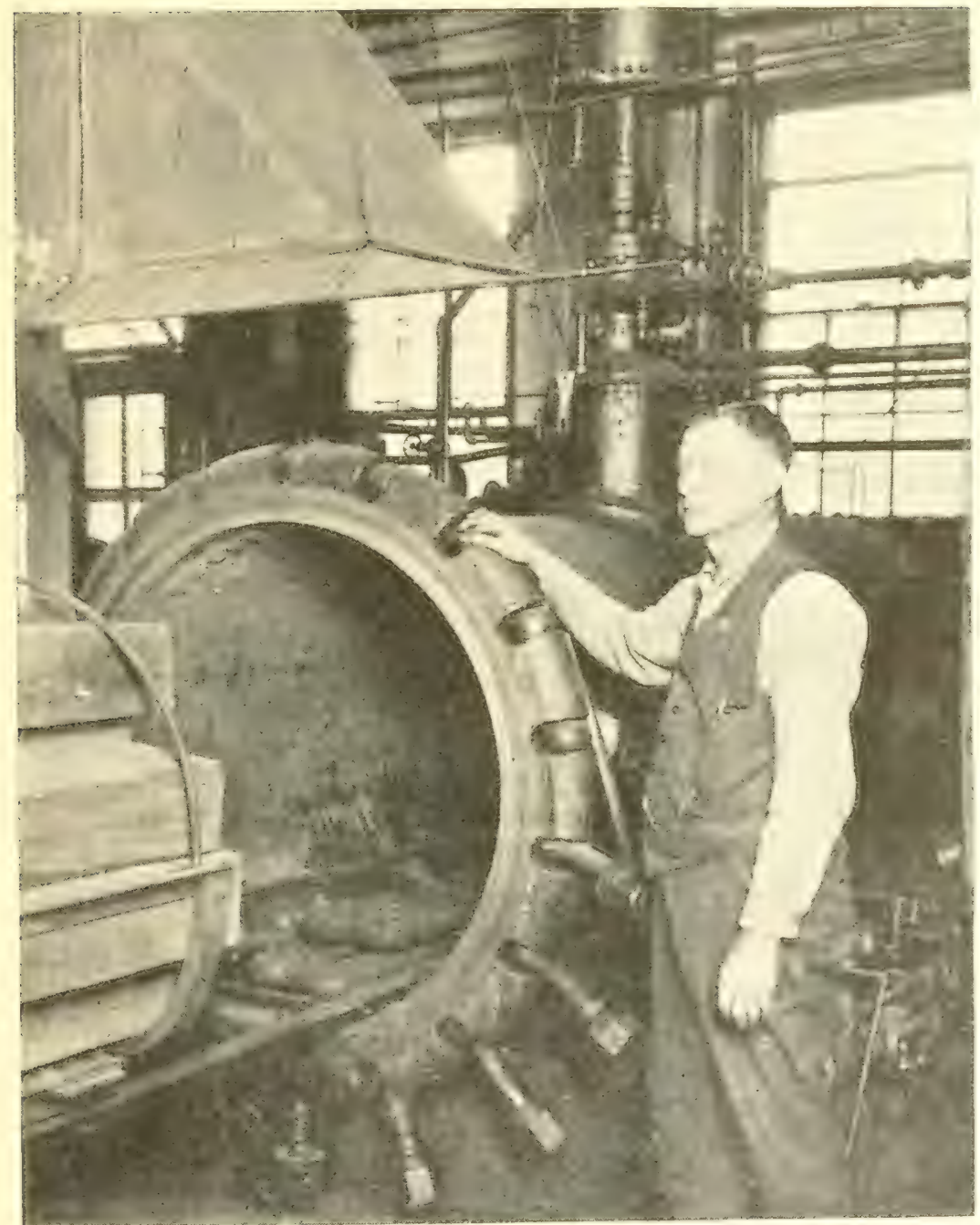

The life of railroad ties treated with preservatives is often double that of untreated ties. The illustration shows some red oak ties about to undergo an experimental treatment with creosote in the pressure cylinder. Afterwards they will be placed in actual service in one of the test tracks maintained by the railroads in cooperation with the Laboratory. 


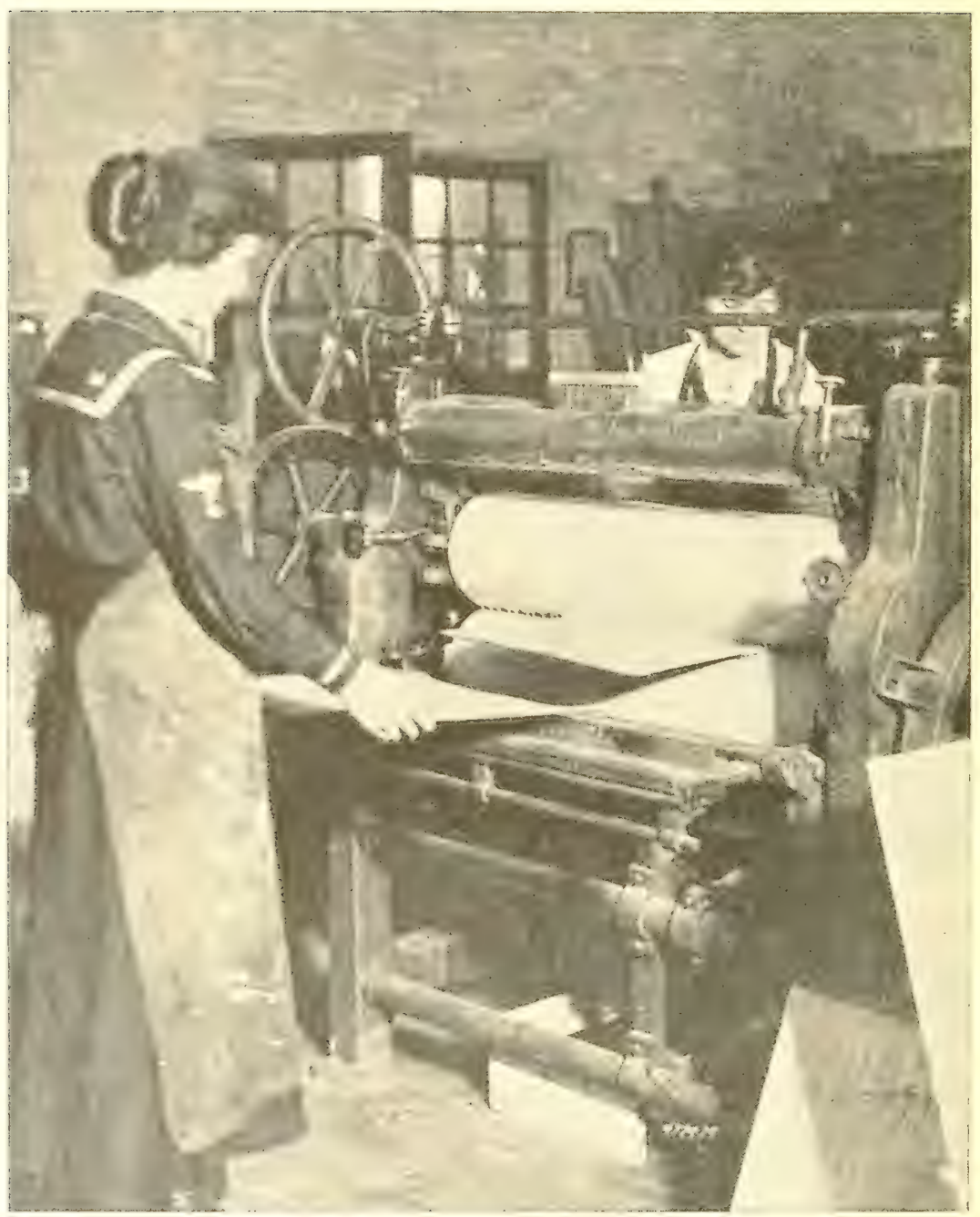

In the manuficture of water-resistant plywond with casein glue, the glue is applied cold to the veneer sheets by means of a mechanical glue spreader. The sheets are then placed one on top of another in a press. 
Closely related to the work on wood preservatives are investigations of preservative processes. These include the relative efficiency of commercially established processes and of new or proposed ones, as well as the fundamental principles involved in the various conditions of temperature and pressure, and other factors entering in the treating process.

A third class of wood-preservation studies deals with the suitability of various species for treatment, including the relative resistance to impregnation and decay and the best methods of preparing them for treatment.

The protection of wood against fire is another Fireproofing. important field in wood preservation. The annual fire loss in the United States is estimated at $\$ 250,000$,000 , and is very much higher than the fire losses in European countries. This difference is due largely to the greater proportion of wooden construction in the United States. Fireproofing the wood or designing the structure so as to offer the least fire hazard are ways of reducing the fire loss and at the same time cutting down the amount of material needed for rebuilding, thus reducing the drain on our forests.

In connection with the manufacture of plywood, studies have been made of animal glues, such as those made from hide, bone, and other products; and standard methods of testing have been developed. A suitable "standard glue" for aircraft work and high-class joint work in general has been developed and samples made available to manufacturers and users. This is the glue adopted as standard by Army and Navy aircraft bureaus.

The development of water-resistant glues of several types, including casein glues and blood-albumin glues, has been progressing for several years, and a number of high-grade glues have been perfected. Tests and experiments are being carried forward to improve these glues still more, especially in their resistance to moisture. Methods of testing for the strength and water

Glues for Plywood.
Processes of Preservation.

Suitability of Species. 


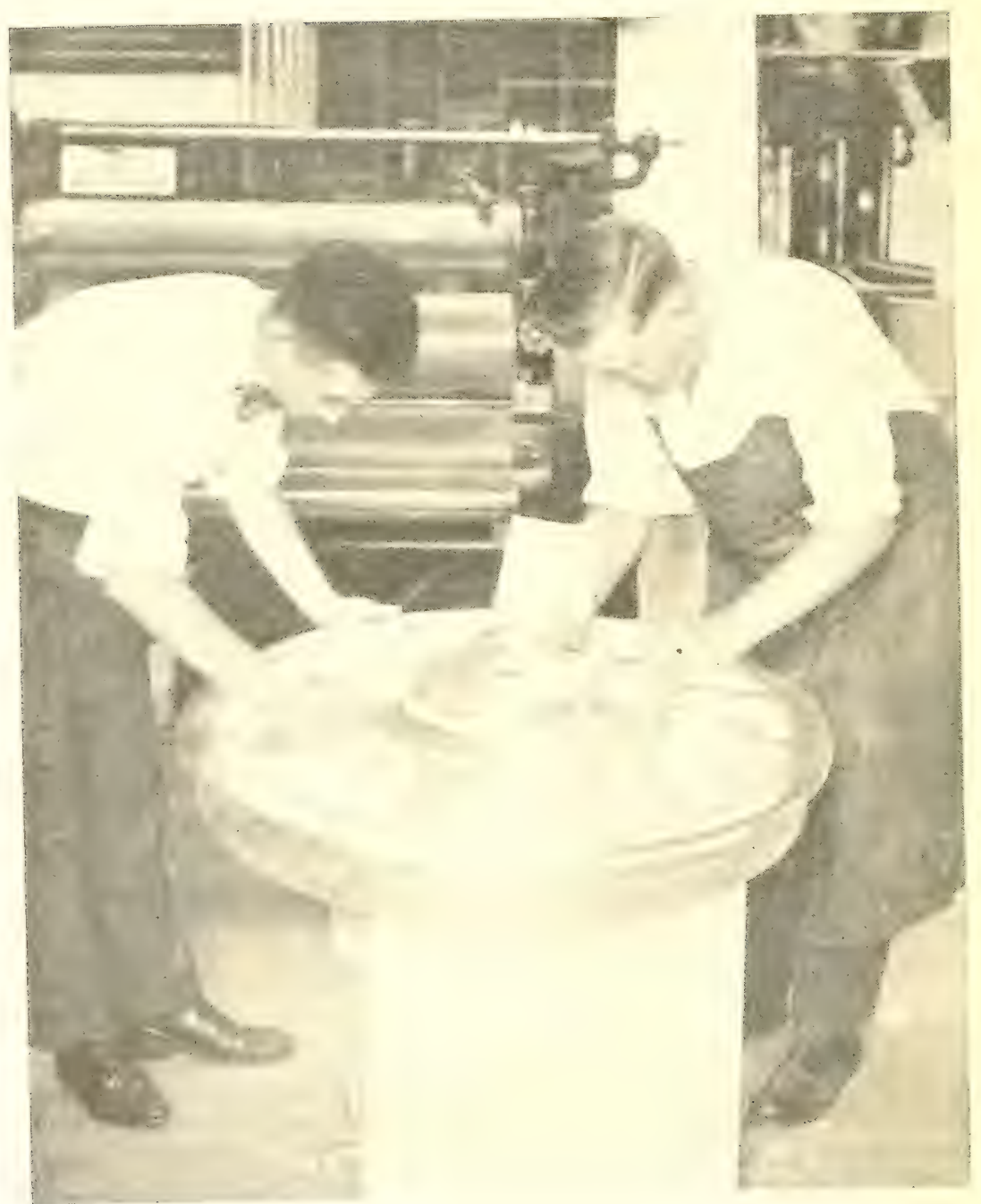

Wooden patterns for castings can be made practically moisture proof by an aluminum leaf coating and so prevented from warping, swelling, or shrinking. Car wheel patterns protected in this way are now in use by several large fuundries. 
resistance of plywood have been developed and specifications drafted for the glues and the plywood, as well as for the raw material from which the glues are made. These specifications have been adopted by the Army and Navy aircraft bureaus.

One of the lines of investigation to be taken up recently is the determination of possibilities and best practices in the design and construction of structural Laminated and Built-up Parts. members built up of small pieces glued together. These investigations were carried out intensively on aircraft parts, such as wing beams and struts, when the success of the aircraft program was threatened by a sudden shortage of suitable material in the required sizes. Additional intensive work is under way on aircraft propellers to determine the best species to use and the best conditions of manufacture and allowable limits for specific gravity, moisture, and direction of grain in individual laminations. The knowledge gained is being applied to extensive investigations of the use of laminated and built-up construction in the various wood-using industries for the manufacture of such articles as shoe lasts, hat blocks, bowling pins, wagon bolsters, and wheel hubs.

The Laboratory has done considerable work on the moisture resistance of various wood coatings used on airplane propellers, and a very efficient aluminum leaf coating has been developed which affords protection against moisture over long periods of storage. Tests are now in progress on the durability of these coatings. - Other work on wood finishes is contemplated. 


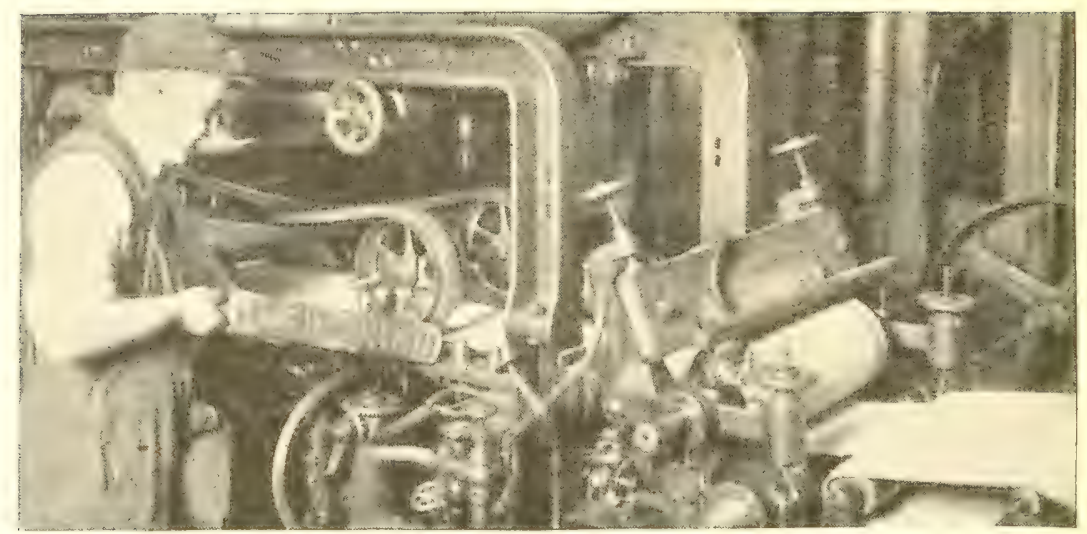

\section{Pulp and Paper.}

IHE constantly decreasing supply of suitable pulpwoods and the ever-increasing demand for paper of all kinds, especially newsprint paper, have combined to produce so serious a situation that investigations into methods of conserving the supply of pulpwood and increasing the production of paper are of paramount importance.

Processes of The Laboratory is conducting experiments on Pulp and Paper Making. methods of making wood pulp and has already developed several important improvements in the standard chemical processes. A ground-wood branch laboratory was operated at Wausau, Wis., for several years, at which the best conditions for grinding pulp were determined. The work of this laboratory was completed in December, 1913, and the results published in a series of bulletins.

Suitability of A very important field of research lies in determining Species. the suitability of various little-used woods as substitutes for those most commonly used. Practically all available species which give promise of suitability are being investigated, and proper methods of grinding or cooking of most of the important ones have already been worked out. 


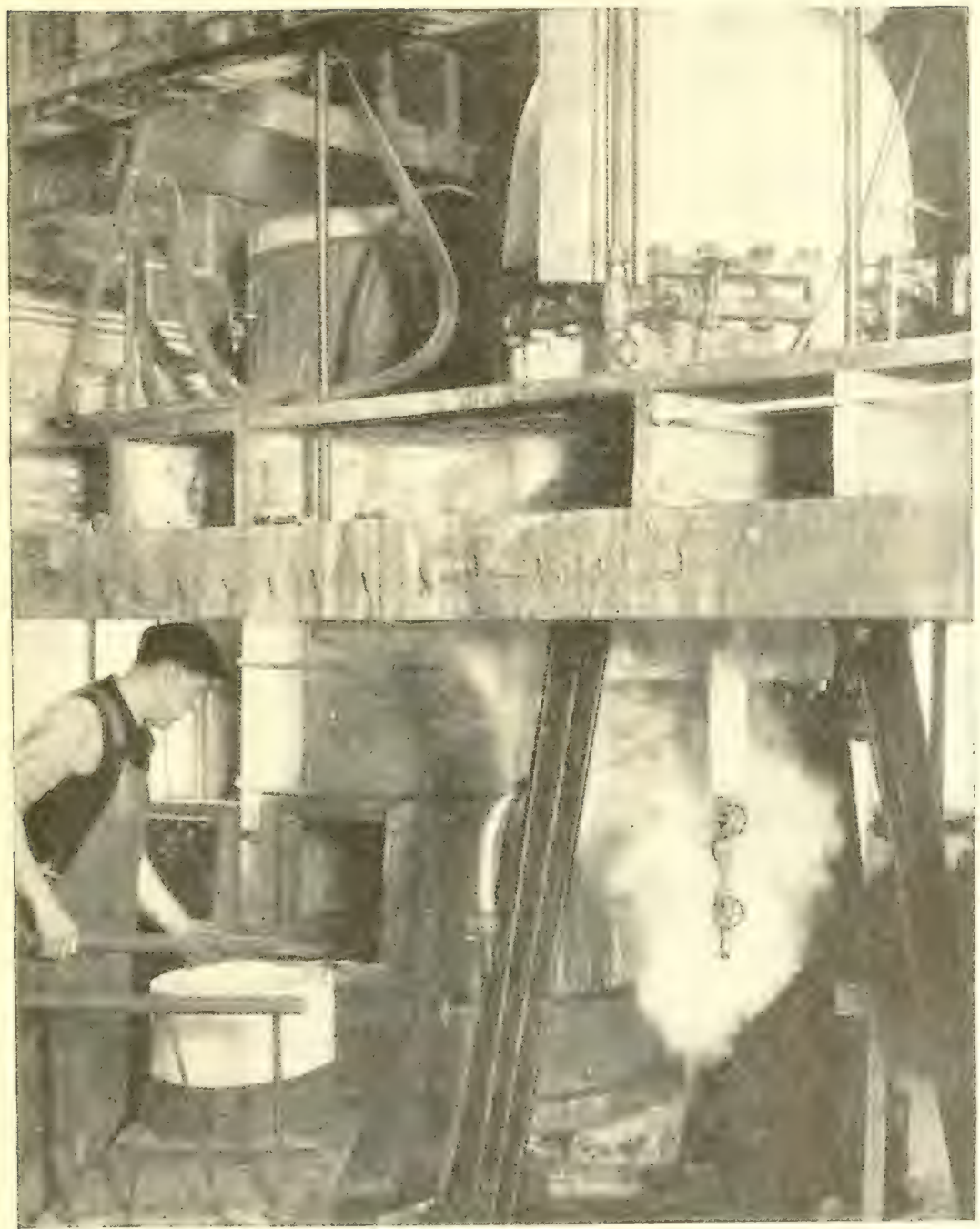

Special small-scale digesters for the manufacture of chemical pulp provide facilities for the study of pulping problems at a moderate cost, preliminary to a cooperative mill test. 
Utilization of Waste.

Studies of waste utilization in the pulp and paper industry have been in progress for some time along a number of distinct lines. For example, feasible methods of turning sawmill waste, such as slabs, into pulp have been determined. The use of a certain percentage of spent tan bark in the manufacture of roofing felts has been investigated and a method developed whereby what was formerly a waste of the tanning industry is now in profitable commercial use. The possibility of using hemlock bark waste for tannin has also been demonstrated.

A commercially feasible method of recovering both the paraffin and the fiber from waxed paper trimmings has been developed. Studies of the wastes incident to the pulp industries, such as sulphite waste liquors and soda liquors, in which are now carried off approximately half of the wood that enters into the digesters, are to be undertaken intensively as soon as funds and equipment become available. The suitability for paper making of hull fiber and second-cut cotton linters, formerly of little value, has been demonstrated and a method of preparation worked out that has proved commercially successful.

Pulp Decay. A recently begun investigation of the deterioration of pulpwood and wood pulp through fungous infection, now estimated at $\$ 5,000,000$ a year, is leading to the proper remedies for this great economic loss.

Special L'ses. The possible use of wood pulp as a substitute for other material in various products has been demonstrated in a number of instances where the Laboratory has suitable equipment or where arrangements could be made with manufacturers. Molded articles, such as buttons and electrical fittings; compounds of cellulose, such as smokeless powder, lacquers, and artificial silk; and waterproof containers are examples of woodpulp products the commercial use of which is possible whenever the relative costs of the pulp and of the raw materials in use make them practicable. 


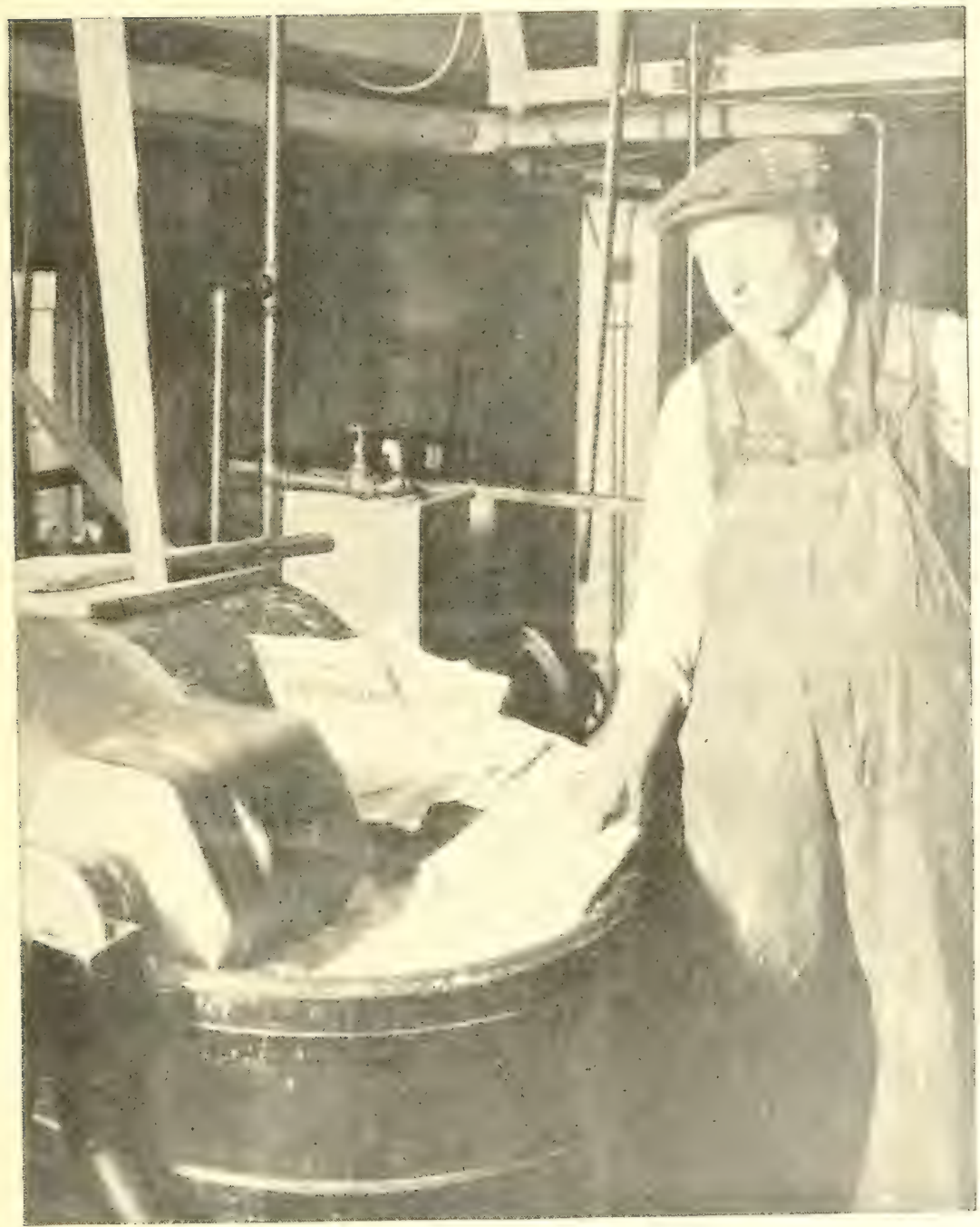

Old newspapers can be de-inked by the use of bentonite, a highly colloidal clay, to which the inls particles adhere after being loosened from the paper in the pulp beater. The pulp is then ready to be used again in the manufacture of newspaper. 
In studying the relative merits of pulps obtained from different woods, methods and instruments have been devised to determine various properties, such as ease of bleaching, freeness of stock, and tearing strength of paper. Methods of liquor analysis have been devised, and also instruments to control manufacturing operations, such as recording hydrometers and liquor samplers. 


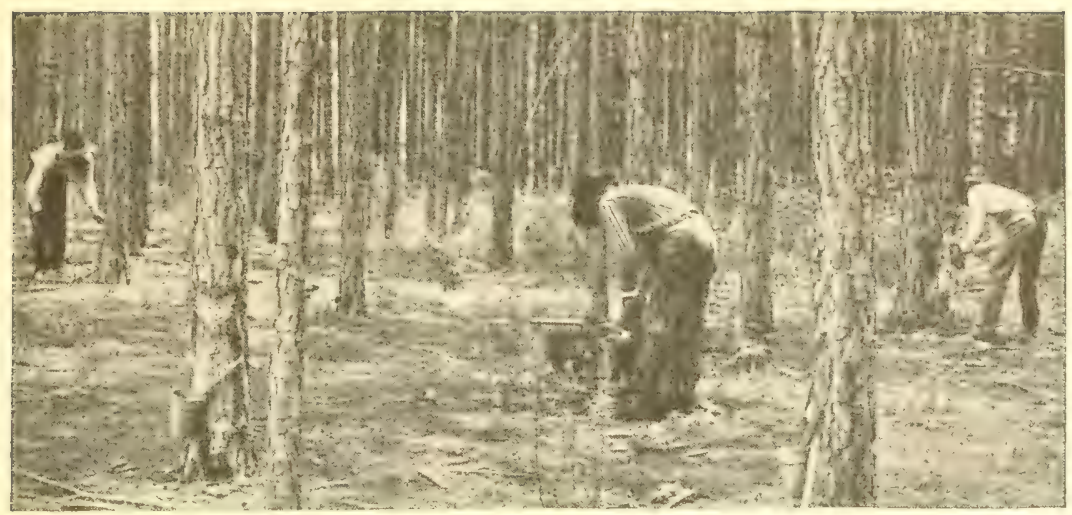

\section{Derived Products.}

7 HE distillation of hardwoods for the production of Hardwoud wood alcohol, acetate of lime, and charcoal has

been a well-known commercial process for many years and has offered one of the best methods for the utilization of hardwood wastes, such as tops, limbs, and slabs. The first work of the Laboratory along this line was a study of the comparative value of different species as distillation woods-at that time only beech, birch, and maple were used commercially. All the important hardwoods have been tested, and several new species, such as oak and hickory, are now in use.

Methods have been developed whereby the yield of alcohol and acetate could be considerably increased by a system of temperature control without extending the time of distillation and with a decrease in the amount of fuel required. These methods have been adopted by most of the commercial plants. Encouraging results have been obtained in work now under way on other methods for increasing the yields, such as the treatment of the wood with chemicals previous to distillation.

Considerable work has been done at the Laboratory on methods for utilizing the hardwood tar produced Flotation Oils. by wood-distillation plants, which has so far been used 
almost entirely as fuel at the plants. The production of flotation oils from hardwood tar is a promising method of utilization which has been the subject of much investigation of the Laboratory. Several satisfactory flotation oils have been produced, and the commercial utilization of hardwood tar is increasing.

Resinous The distillation of longleaf pine stump wood and Wood Distil- "lightwood," primarily for wood turpentine, pine oil,
lation. and rosin, has been a small industry for some time, and for the more resinous classes of waste wood it offers a satisfactory method of utilization. The Laboratory has carried on investigations and obtained valuable results on more efficient methods for distilling the wood and refining the products. Other species than longleaf pine have also been studied, for the most part in test runs at commercial plants.

Turpentine and Rosin.

Very valuable results have been obtained by experimental field work in improving methods of obtaining crude turpentine from the tree. A new method has been developed which has increased the yield of turpentine and decreased the bad effect on the tree and reduced the danger from fire. This method has been adopted by almost the entire industry. A complete study has also been made of the amount and composition of the turpentine from several western pines. The changing conditions in this industry due to the rapid depletion of virgin stands of longleaf pine make it desirable to develop turpentining methods which are especially applicable to second-growth timber and to long-continued operation on the same tree, instead of the usual three to five year operations.

Ethyl (grain) A promising method of utilizing profitably large Alcohol. quantities of wood waste depends upon the conversion of the cellulose into ethyl alcohol. It has long been known that wood cellulose can be converted into fermentable sugar by suitable treatment with dilute acids at high pressures, but until recently the process has not met with commercial success. Investigation at the 
Laboratory involved the design and installation of apparatus of semicommercial size and a detailed study of the influence of such variables as pressure, temperature, time concentrations of acid and water, and many others. Partly as a result of these experiments the process is now a commercial success and offers a new means of utilization which will be a source of heat and power of immense economic importance. The two plants now operating in this country have a combined daily capacity of about 9,000 gallons of 95 per cent alcohol. The high quality and purity of the products are attested by the great demand for this alcohol for the preparation of pharmaceuticals and colognes.

In addition to investigations upon the production of ethyl alcohol from wood, extensive studies are in progress upon the production of this important commodity from waste sulphite liquor. The enormous quantity of waste sulphite liquor produced daily at the paper mills makes the development of a means of utilization of this waste material, which contains almost one-half of the original wood, of the greatest importance.

Another study that has recently been started is the production of a stock food from sawdust. As in the Sawdust for Stock Food. manufacture of ethyl alcohol, the cellulose is first converted into sugar by treatment under pressure with dilute acid, and this sugar, after being extracted and boiled down to a thick molasses, is mixed with the sawdust residue. While this investigation has not been carried far enough to warrant final conclusions, preliminary experiments upon the feeding of cattle have been highly encouraging. This so-called "wood meal" has been substituted for one-fourth the ordinary grain ration of the cattle, with a resulting increase in their weight and no decrease in the yield of milk.

Other products derived from trees or forest materials Other and therefore within the scope of the I aboratory's Derived work, are tannins, gums, balsams, essential oils ex- 


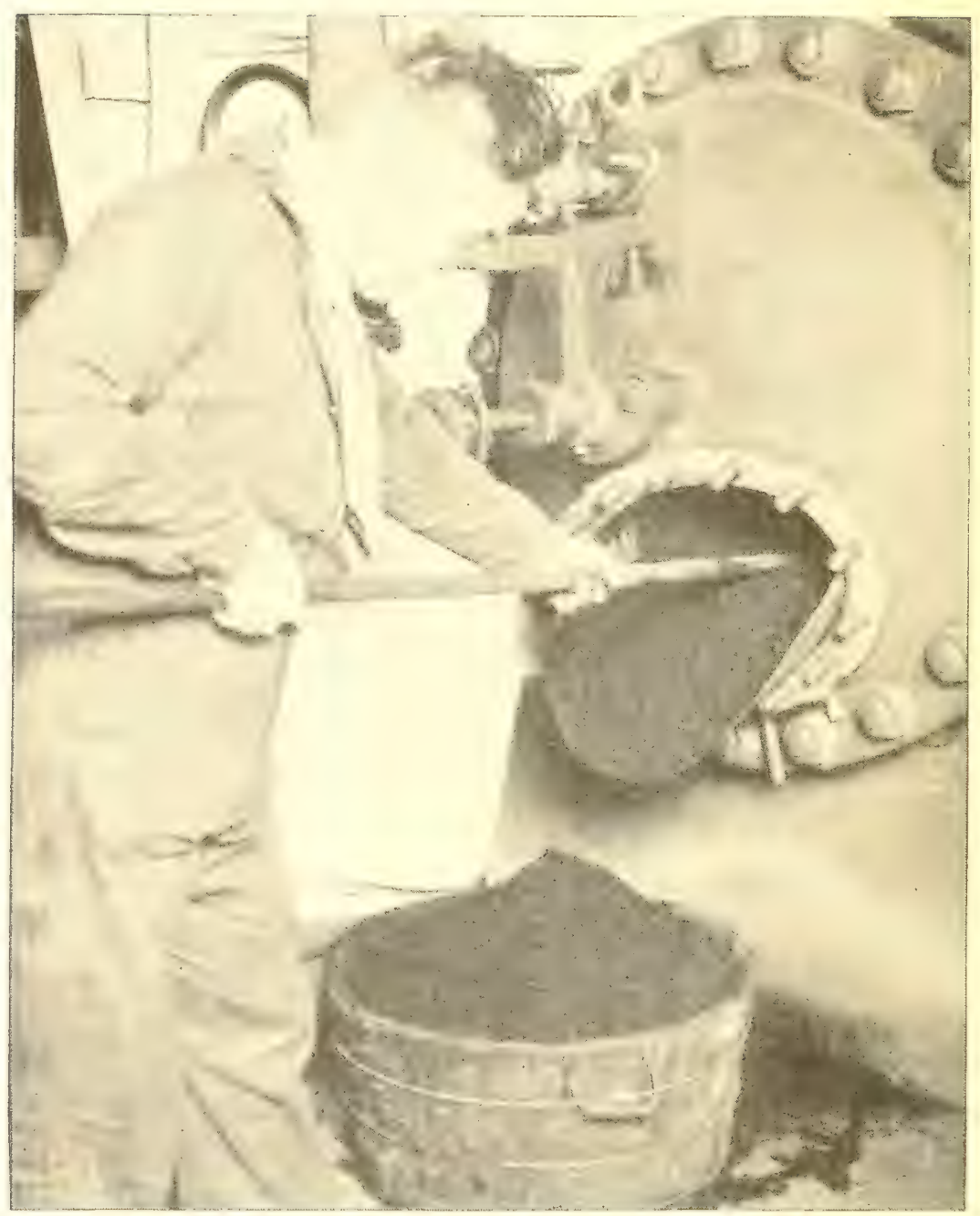

The first step in the manufacture of cattle food from sawdust is to cook the sawdust with dilute acid in a steam pressure cylinder. This converts a part of the wood into sugars and renders the remainder more digestible. Hydrolized sawdust is being successfully fed to cattle as a considerable part of their concentrate ration. 
tracted from the wood, roots, bark, or leaves of various trees, and producer gas manufactured from wood. The chemical derivatives of cellulose, while not yet touched upon, also offer a fertile field for investigation.

Fundamental knowledge of the chemical composition of any material undergoing thorough study is essential, and this need in the case of wood will eventually be supplied through an elaborate investigation under way at the Laboratory. Methods of analysis have been standardized and a number of species of wood have been analyzed.

The selection of the most suitable woods for the manufacture of separators for storage batteries and various kinds of chemical apparatus requires a better knowledge of the chemical composition and properties of the various woods. The more extensive utilization of waste wood by chemical means also depends upon the accumulation of data on the chemical composition of the different woods. The methods of analysis developed in this work have been of much value in other lines, such as the study of decay in pulpwood, the special use of paper pulp, and the use of hydrolyzed sawdust as a stock food.

Chemical Composition of Wood. 


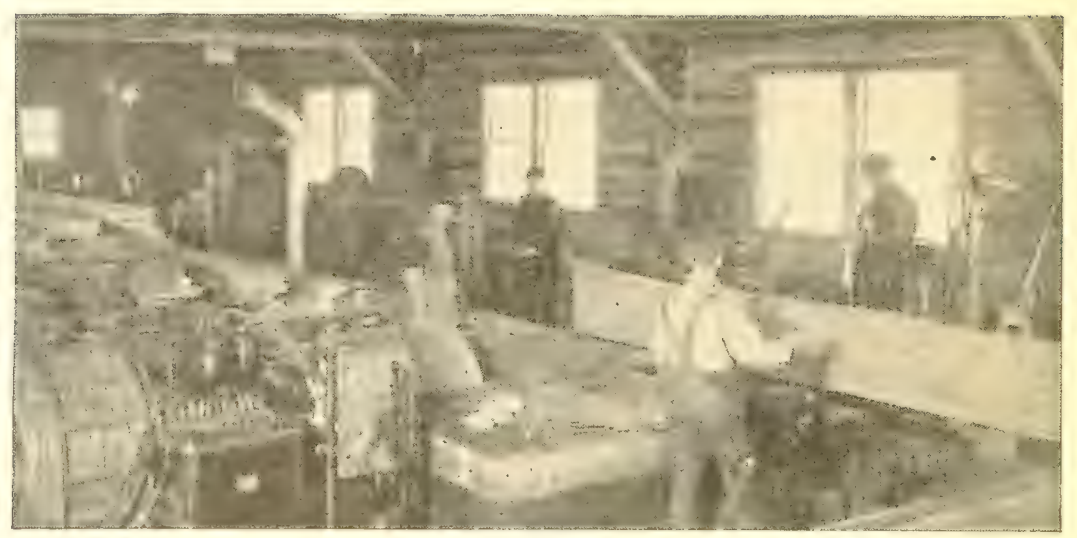

\section{Industrial Investigations.}

Mechanical
Utilization of 1 FCHANICAL, as well as chemical processes offer Waste and Low-Grade Material.

Survey of Wood Waste.

a promising field for the profitable utilization of wood now wasted and for the steadily increasing amount of small and low-grade material coming from secondgrowth stands. Only 30 per cent of the wood in a forest now gets into the form of seasoned, unplaned lumber. Of this an additional 10 to 25 per cent is lost in the process of manufacture. In extreme cases as little as 3 per cent of the wood in the forest may reach the finished product.

How to reduce to a minimum these losses in logging and manufacture constitutes a research problem of farreaching scope and significance. The Laboratory will undertake a comprehensive survey of the present practice and its results in some of the more important wood-using industries. This will be followed by more intensive investigations of equipment, methods, and processes with a view to determining possible modifications and improvements. These investigations will be conducted both in the woods and at the mill and will include studies leading to increased efficiency of operation as well as to closer utilization.

Dimension Stock.

The manufacture of small-dimension stock offers a striking example of the opportunity for reducing present 
wastes in manufacture. It has been estimated that all of the 5 or 6 billion board feet used each year in the manufacture of articles made from such stock could be secured from material now wasted. Whether or not this is true, there is no question that present wastes could be greatly reduced by standardizing dimension sizes, by cutting dimension stock directly from the log instead of remanufacturing it from lumber, and by an interchange between industries that would result in the utilization by one industry of what is now regarded as waste in another. Studies along these lines have been undertaken by the Laboratory and will be exiended as rapidly as possible.

Another problem of first importance has to do with finding a profitable and economical use for the small sizes and low grades on which we shall have increasingly to depend as the virgin forests are replaced by second-growth stands. This problem includes also the finding of uses for species now without markets. To a considerable extent the practice of forestry is dependent on developing methods by which the material of all species produced by these stands can be used in place of the high-grade material of a few species from virgin forests to which we have hitherto been accustomed. This involves not only perfecting the technique of built-up and laminated construction, but the introduction of new uses and new methods of manufacture. Investigation of these and related problems will go far toward enabling us to eliminate present wastes and to make the most of our wood supply.

A number of mill-scale studies have been made upon various species to determine precisely the grade, quantity, and cost of lumber cut from logs of a given Mill-Scale Studies and Grading size and grade; and further studies of this character are planned. They are of direct value as a check upon mill efficiency and furnish a reliable basis for appraising the stumpage value of National Forest and other standing timber. Similar studies of the efficiency

Second Growth Stands. 
and cost of manufacturing lumber will be made as an integral part of the comprehensive survey of equipment, methods, and processes emplored by the rarima woud-using industries. Intensive studies of lunibengrading rules and lumber sizes, with a view to making them more uniform and better suited to the needs inf the eomsume will also be undertaken. 


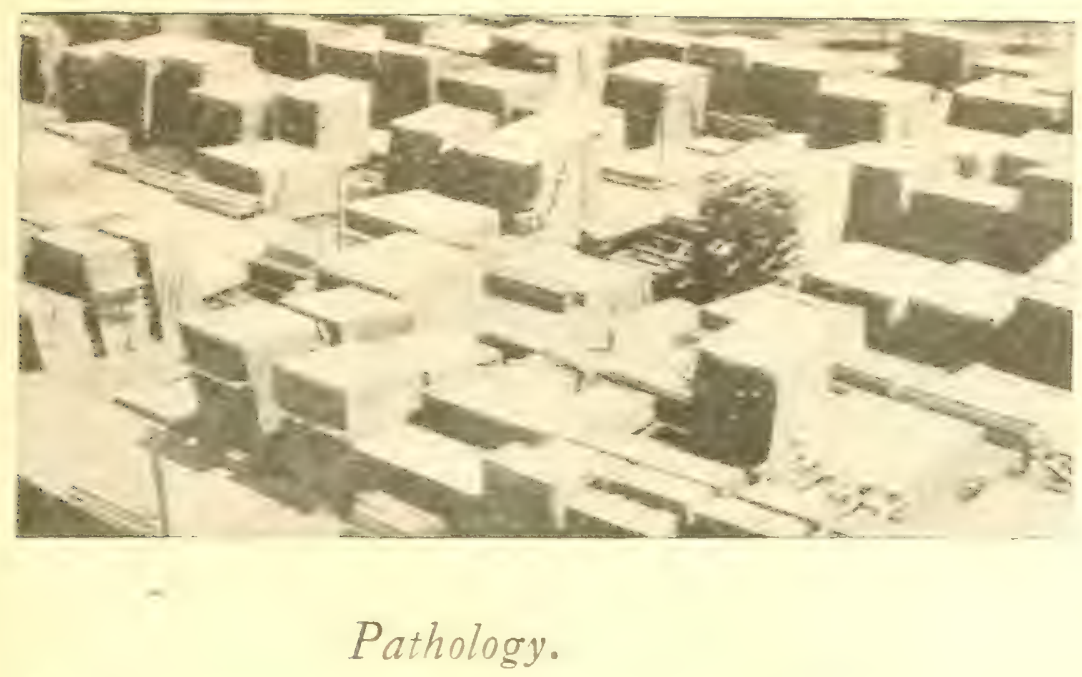

$\mathrm{T}^{\mathrm{HE}}$ work of this section is conducted by' the Bureau of Plant Industry of the Department of Agriculture. General studies of the durability and decay of wood are carried on.

The relative durability of different woods and the Durabileffect of moisture and wood-destroying fungi upon the life of the wood have been studied for many kinds of Wood. American woods. Data have been obtained upon the least and most favorable temperatures for the growth of fungi and the amount of heat required to stop their growth. An application of this work is the control of so-called "dry rot" in buildings.

The toxicity, or poisonous effect, of wood preservative has been studied and the antiseptic effectiveness of different treatments determined.

Extensive investigations to determine the prevalence Decay in of decay in buildings throughout the United States Building have been made, and from information collected over Timber. a 10-year period recommendations have been developed as to changes in architectural design, proper species for different uses, and suitable antiseptic treatments.

Unsuspected losses by wood users resulting from improper storage of wood aggregate several million of Storage dollars annually. Studies and recommendations have Yards. 


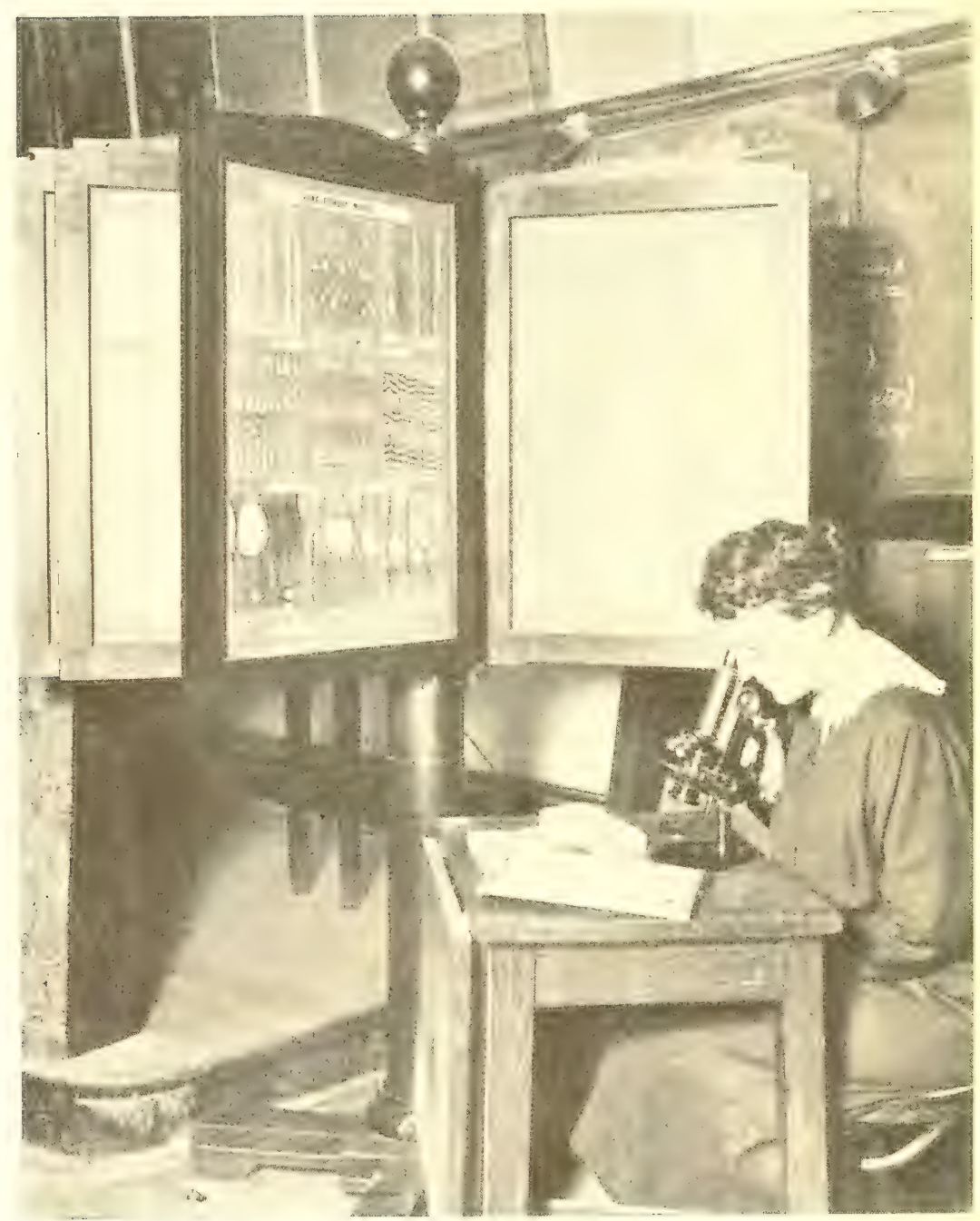

With a microscope it is possible to identify wood from practically any of our native trees. The revolving chart shows the diversity in wood structure brought out under a lens. 
been made on storage of general lumber stocks at sawmills and retail yards, the storage of manufactured wood products, such as vehicle parts, boxwoods, veneers, and staves, and also the storage of pulpwood and pulp. Infection begun in the yard frequently is passed on in the manufactured product to other wood with which the infected material is used. 


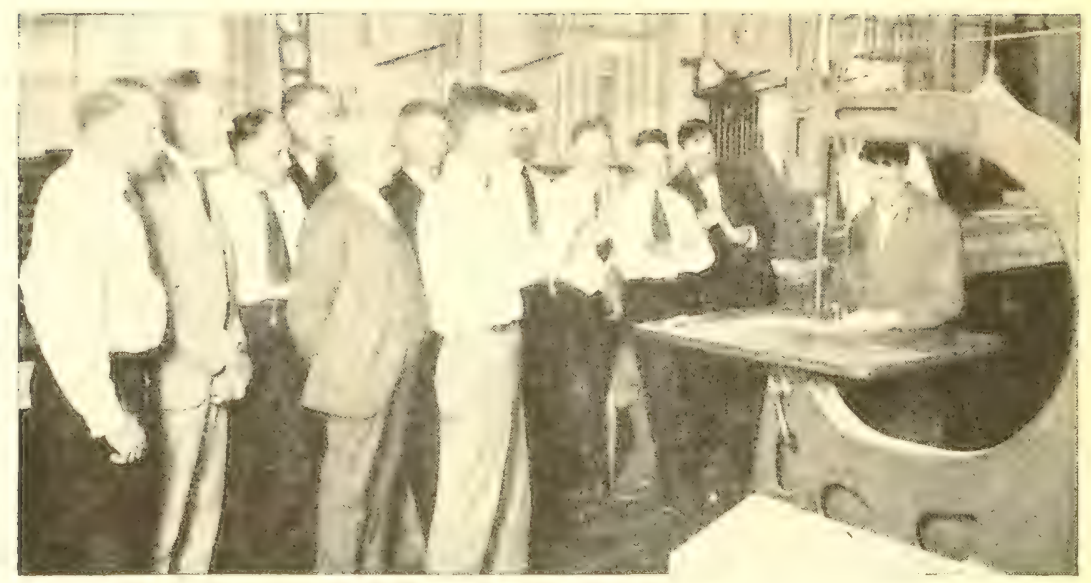

\section{How to Use the Laboratory.}

Information
Free. its information available to the public as rapidly as possible. This it does through personal contact and through reports written during the progress of investigation and upon their completion, so that all information of value is published, either as bulletins or circulars by the Government, in technical notes, by correspondence, or as special articles in trade journals and technical and scientific papers.

Investigations are undertaken both independently and on a cooperative basis, but all investigations must be of a research character that will give information or results of value in attaining the general objects aimed at by the Laboratory.

Cooperation. The Laboratory works in cooperation with the lumber-manufacturing and wood-using and timberproducing industries most directly concerned with the subjects or problems under investigation, as well as with State forest organizations and forest schools. As a general rule, no investigation conducted by the Laboratory is regarded as complete until the results obtained experimentally have been checked on a commercial scale and their industrial application determined. 
This is ordinarily accomplished through cooperation with individuals or companies that use wood and are commercially interested in developing new or better processes or products.

The Laboratory equipment is of experimental and semicommercial size, and it aims to carry results and ideas as close to commercial demonstrations as facilities and appropriations will permit before applying results at commercial plants.

In cases of formal cooperation, there should be a remuneration to the Laboratory depending on the cost of the work done for the cooperator, including the time and expense of the members of the Laboratory detailed to the project, and its general supervision. When practically all of the work proposed is investigative and the results of value chiefly to the general public, the charge to the cooperator may be comparatively low or eliminated altogether.

Whenever practicable, arrangements are made with cooperators or others especially interested in the invesMaterial for Experiments. tigation to furnish all the material necessary for the work. As far as practicable, cooperative projects are covered by written agreement whenever cooperative investigations of a specific character are to last six months or longer, or when the total expenditure of the Forest Service on the work will exceed $\$ 100$.

An arrangement which has resulted very satisfactorily in several cases is the assignment to the staff of the Laboratory of men from the organization of the cooperator.

Anyone is at liberty to correspond with the Laboratory about particular problems dealing with the utilization of wood and will receive answers based on whatever information is available on the subject. The staff of the Laboratory is also available for consultation work, provided the solution of the problem under consideration will further its general research work, or has direct bearing upon it.

Pérsonal visits to the Laboratory for consultation have proved very satisfactory.

Men Assigned to Laboratory.

Consultation on Special Problems. 


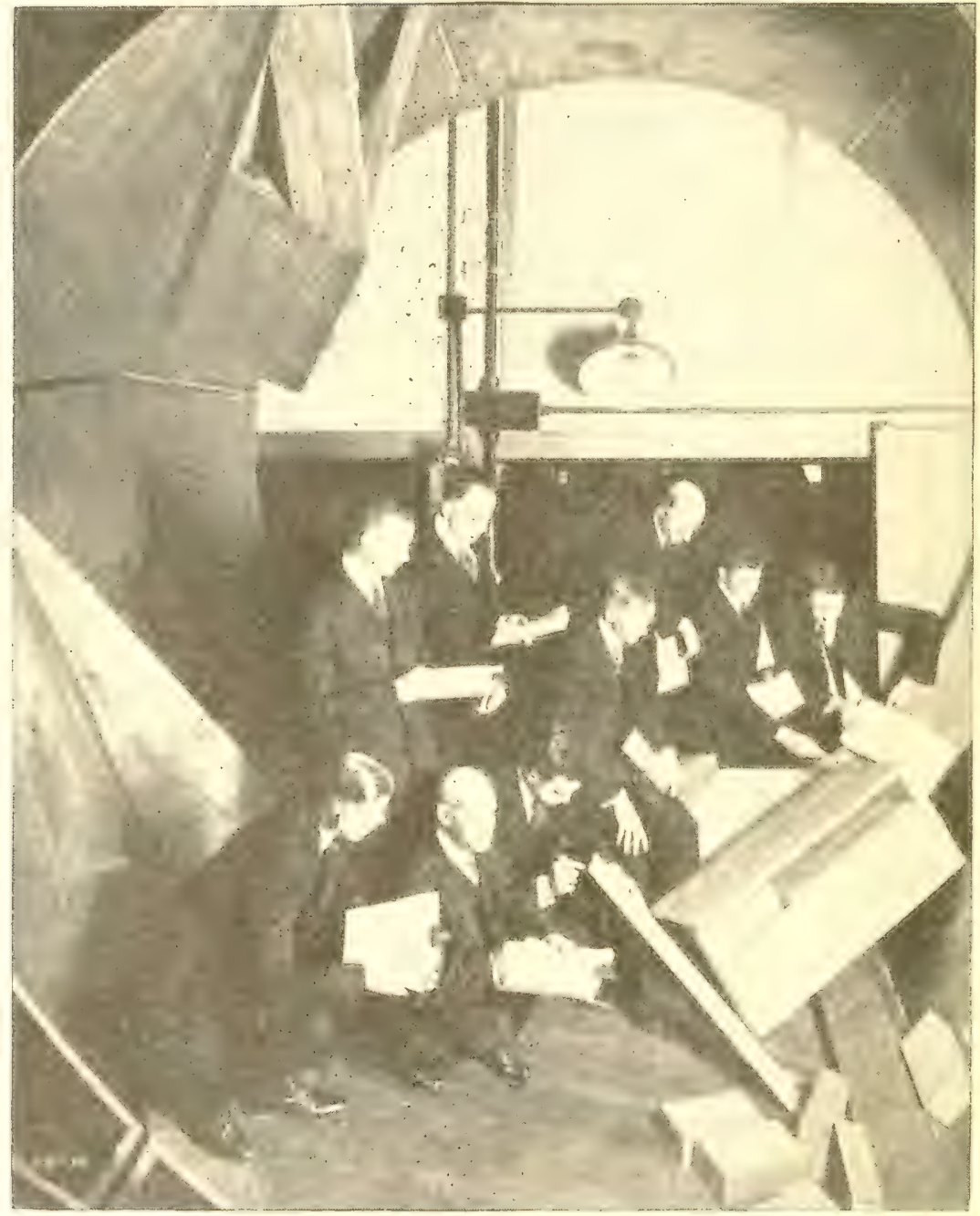

Classes in boxing and crating at the Laboratory make use of the 1t-foot drum testing machine to investigate the serviceability of shipping boxes. The manufacturers and shippers in the group traveled an average of 2,000 miles each to attend the one-week course. 
The Laboratory has a very important function in assisting in the conservation and utilization of National Forest timber. It acts in a consulting capacity to the men in actual charge of the timber-sale work, and with them works out the commercial possibilities of blocks of timber that are ready for cutting and the relative value of the various species for different purposes.

The design, construction, and operation of commer- Operation cial plants for wood preservation, distillation, kilndrying, and similar work may be undertaken in exceptional cases when a new process will be demonstrated and the plant used, at least in part, for experimental work. The Laboratory may make suggestions regarding the construction and operation of such plants, referring applicants, however, to consulting engineers for assistance as to details.

The Laboratory may, on request, examine the methods of individuals or companies used in handling forest products and prepare plans for improving such methods, provided that the purpose is primarily to reduce waste and to obtain information of general value to the industries concerned.

Two short cooperative courses of instruction are given monthly at the Laboratory-one in kiln-drying, Courses of Instruction. the other in boxing and crating. These courses are of particular value to superintendents, lumber and production men, and foremen in wood-using plants. The instruction is under the supervision of a staff of competent specialists and the enrollment is limited to 16 men in each course, so that proper attention may be given to individual problems. Priority of application governs admission to the courses, and the classes are usually filled for two or three months ahead.

Detailed information concerning any of the work of the Laboratory will be gladly furnished. Inquiries should be addressed to the Director, Forest Products Laboratory, Madison, Wis. 

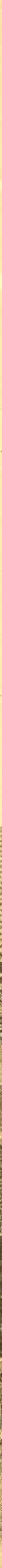


\section{LIBRARY OF CONGRESS}

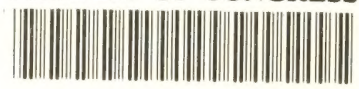

00008980949 